\title{
Clinicopathological Characteristics of Colorectal Submucosal Carcinoma with Lymph Node Metastasis
}

\author{
YASUMI ARAKI, HIROHARU ISOMOTO, KAZUO SHIROUZU, KAZUHIDE MIURA, \\ HIROKI IWANAGA, AKIRA OKITA, TERUO SASATOMI, YUTAKA OGATA, \\ TATSUHISA MORODOMI AND TERUO KAKEGAWA \\ Department of Surgery, Kurume University School of Medicine, Kurume, 830 Japan
}

Received for publication June 7, 1993

\begin{abstract}
Summary: The clinicopathological characteristics of colorectal submucosal carcinoma with lymph node metastasis are described. Lymph node positive metastasis was found in $10(11 \%)$ of 87 cases. The depth of submucosal invasion was classified as $\mathrm{sm}_{1}, \mathrm{sm}_{2}$ or $\mathrm{sm}_{3}$. Lymph node positive metastases were found in $18 \%$ of the cases at $\mathrm{sm}_{2}$ or more, in $31 \%$ of those without adenomatous components, in $39 \%$ of those with positive lymphatic permeation, in $41 \%$ of those with positive budding, and in $56 \%$ of all the moderately differentiated adenocarcinomas. These characteristics are risk factors and are important for the prediction of lymph node metastasis from colorectal submucosal carcinoma. Bowel resection with lymphadenectomy is indicated in the presence of any one or more risk factors.
\end{abstract}

Key words: submucosal colorectal cancer-lymph node metastasis - budding-lymphatic permeation-adenomatous component-risk factors.

\section{Introduction}

With increased public interest and with new developments in diagnostic techniques and group cancer screeing, cancer in the large bowel is increasingly being detected at an early stage in Japan, as is gastric cancer. According to the General Rules for Clinical and Pathological Studies on Cancer of Colon, Rectum and Anus (Jinnai, 1983), early colorectal cancers are either those in which the depth of cancer invasion is limited to the mucous membrane (mucosal cancer) or those in which invasion reaches the submucosa (submucosal cancer). Early colorectal cancer in most cases is treated by endoscopic surgery. Local ex- cision is considered sufficient for mucosal cancer, since there is no lymph node metastasis. When submucosal cancer is diagnosed following endoscopic resection, intestinal resection with lymph node dissection must be considered and is based on any findings of positive lymph node metastasis. In the present study, lymph node metastasis of colorectal submucosal cancer was investigated clinicopathologically to determine the choice of treatment for early colorectal cancer.

\section{Materials and Methods}

Eighty-seven lesions of colorectal submucosal cancer resected surgically or

Correspondence and reprint requests to: Yasumi Araki, M.D., The First Department of Surgery, Kurume University School of Medicine, 67 Asahi-machi, Kurume, 830 Japan. 
endoscopically during the period from 1980 to 1992 were studied. Each lesion was embedded in paraffin and prepared in $3 \mathrm{~mm}$ wide sections and stained by hematoxylin-eosin for microscopic examination. The lesions were classified morphologically according to the macroscopic classification of early cancers-protruded type (Ip: pedunculated, Isp: subpedunculated and Is: sessile), flat-elevated type (Ila: flat-elevated without depression and $\Pi \mathrm{Ia}+\Pi \mathrm{Ic}$ : flat-elevated with depression), and depressed type (IIc: slightly depressed) (Fig. 1). The histopathological classification of the depth of submucosal invasion followed (Kudo et al. 1984); the submucosal layers from the lamina musculous mucosa to the proper muscular layer were divided into three depths $-\mathrm{sm}_{1}, \mathrm{sm}_{2}$ and the deepest as $\mathrm{sm}_{3}$. With lesions excised endoscopically, the submucosal layer was divided into two layers above and below the lamina mus-

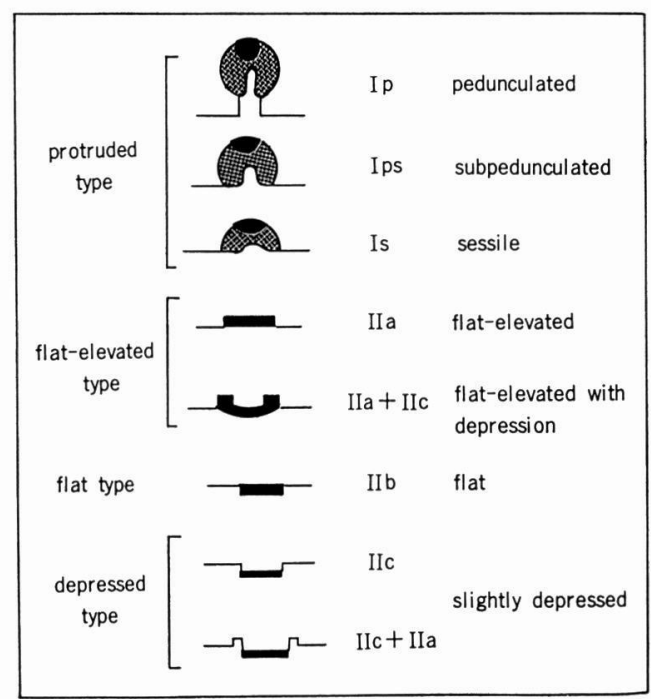

Fig. 1. Macroscopic classification of early cancers - protruded type (Ip: pedunculated; Isp: subpedunculated; IIs : sessile), flat-elevated type (Па: flat-elevated without depression; $\Pi \mathrm{Ia}+\Pi \mathrm{c}$ : flat elevated with depression), and depressed type (IIc: slightly depressed).

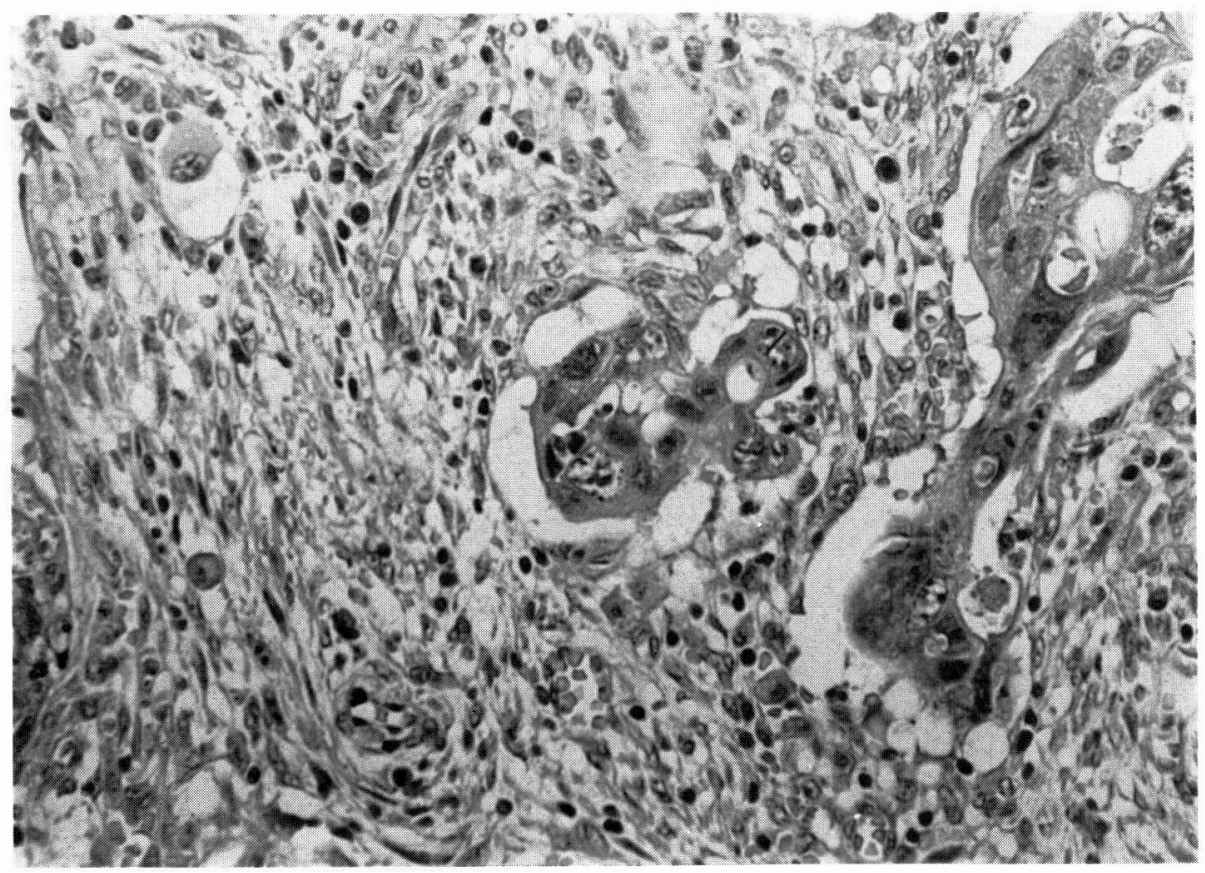

Fig. 2. Microtubular cancer nets and undifferentiated cancer cells that are called budding $(\mathrm{H} \& \mathrm{E}$, original magnification $\times 400)$. 
cularis mucosa - the surface layer as $\mathrm{sm}_{1}$, the deeper layer as $\mathrm{sm}_{2}$, and $\mathrm{sm}_{3}$ for ew $(+)$.

With respect to our definition of budding, microtubular cancer nets and undifferentiated cancer cells, as suggested by Morodomi (1988) and Morodomi et al. (1989), involving a differentiated adenocarcinoma occurring locally as clusters of five or more cancer cells with a tubular structure are designated as a small duct adenocarcinoma. Cancer cells occurring in a solitary fashion without any definitive structure by themselves are considered to be undifferentiated and the occurrence of such cells is designated as "budding" (Fig. 2).

\section{Results}

Distribution of submucosal colorectal carcinoma

The 87 submucosal colorectal cancers were destributed as follows: none $(0 \%)$ in the caecum, $1(1 \%)$ in the ascending colon, $2(2 \%)$ in the transverse colon, 3 $(3 \%)$ in the descending colon, $29(33 \%)$ in the sigmoid colon, $14(16 \%)$ in the upper rectum and 38 (44\%) in the lower rectum. The highest incidences were in the sigmoid colon and rectum.
Colorectal submucosal cancer with positive lymph node metastasis (Fig. 3)

Lymph node metastasis was positive in $10(12 \%)$ of the 87 cases with submucosal colorectal cancer, including 7 males and 3 females, with an age range of 29-72 years. The original lesion in all

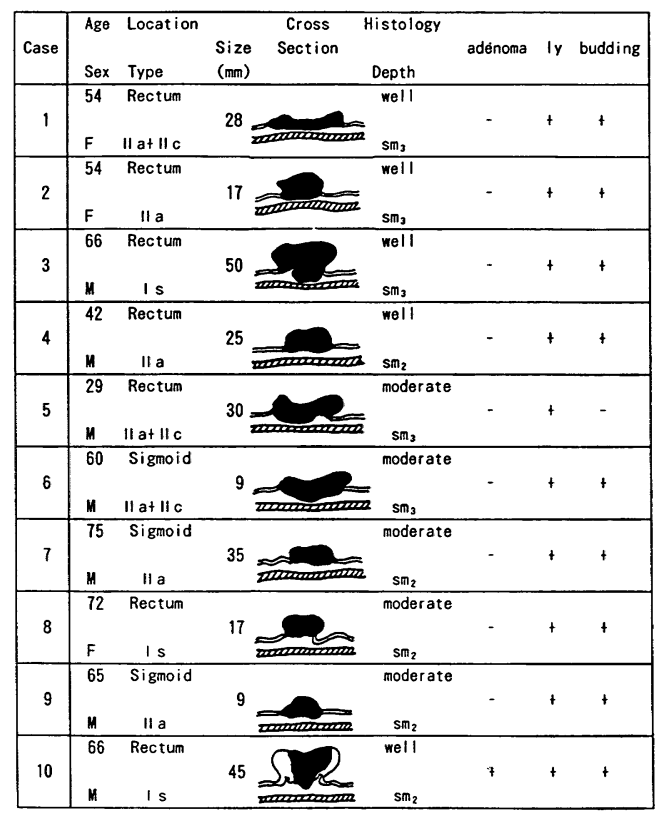

Fig. 3. Ten cases of colorectal submucosal cancer with lymph node metastasis.

TABLE 1.

Histological findings and frequency of lymph node metastasis of colorectal cancer

\begin{tabular}{|c|c|c|c|c|c|}
\hline \multirow{2}{*}{$\begin{array}{l}\text { Risk factors for lymph } \\
\text { node metastasis }\end{array}$} & \multicolumn{4}{|c|}{ Macroscopic Type } & \multirow{2}{*}{ Total } \\
\hline & Ip & Is & ПIa & $\Pi \mathrm{II}+\mathrm{II} \mathrm{c}$, IIc & \\
\hline $\mathrm{sm}_{2}$ invasion & $0(0 / 0)$ & $20(3 / 15)$ & $21(4 / 9)$ & $18(3 / 17)$ & $20(10 / 51)$ \\
\hline adenoma component & $0(0 / 0)$ & $67(2 / 3)$ & $33(4 / 12)$ & $25(3 / 12)$ & $33(9 / 27)$ \\
\hline $1 \mathrm{y}(+)$ & $0(0 / 0)$ & $50(2 / 4)$ & $50(4 / 8)$ & $25(3 / 12)$ & $41(9 / 24)$ \\
\hline budding $(+)$ & $0(0 / 0)$ & $33(2 / 6)$ & $50(4 / 8)$ & $33(3 / 9)$ & $39(9 / 23)$ \\
\hline *mode. diff. adenoca. & $0(0 / 0)$ & $33(1 / 3)$ & $68(2 / 3)$ & $50(2 / 4)$ & $40(5 / 10)$ \\
\hline
\end{tabular}

* mode. diff. adenoca.: moderately differentiated adenocarcinoma 
10 cases was in the rectum or sigmoid colon. Three had a macroscopic morphology Is, 4 were $\Pi \mathrm{Ia}$ and 3 were $\mathrm{Il}+$ IIc. There was no lymph node metastasis in the Ip type. Of the 10 lesions, 2 were smaller than $10 \mathrm{~mm}, 3$ were $11-20 \mathrm{~mm}$, and 5 were larger than $21 \mathrm{~mm}$ at the greatest diameter. There was no correlation between the lesion size and positive lymph node metastasis. Histopathologically, there were 5 well differentiated adenocarcinomas and no poorly differentiated adenocarcinomas. With respect to the depth of cancer invasion, no metastasis was found from $\mathrm{sm}_{1}$ cancers, while 4 cases of lymph node metastasis were found with $\mathrm{sm}_{2}$ and 6 with $\mathrm{sm}_{3}$. Thus an increased incidence of lymph node metastasis occurred from lesions with deeper invasion. All cases of positive lymph node metastases were without any adenomatous component and with positive lymphatic permeation. Budding was observed in 7 cases. The positive findings of budding in Case 6 is representative (Fig. 2). Patient 2 died from metastasis to the liver after a local recurrence. All the other patients are alive without recurrences.

Histopathological findings and frequency of lymph node metastasis from colorectal submucosal cancer

As shown in Table 1, lymph node metastasis was found with $18 \%$ of $\mathrm{sm}_{2}$ or deeper lesions, with $31 \%$ of those without adenomatous components, with $39 \%$ of those with positive lymphatic permeation, with $41 \%$ of those with positive budding, and with $56 \%$ of those which were moderately differentiated adenocarcinomas. These macroscopic classifications are therefore important risk factors for predicting lymph node metastasis.

\section{Discussion}

The discovery of early cancer in the large bowel, especially in the sigmoid colon or in the rectum, has increased considerably with the development of diagnostic techniques such as colonoscopy, and with the increased participation of the general population in cancer screening. When lesions excised endoscopically are discovered to be submucosal cancer, the decision to perform radical surgery remains difficult. Concerning the risk factors for lymph node metastasis and for remnant submucosal cancer following polypectomy or local excision, the highest risks with a positive stump and with a poorly differentiated adenocarcinoma were reported by Morson et al. (1984), the highest risk with an $\mathrm{sm}_{3}$ cancer was reported by Haggitt et al. (1985), while the highest risk with $\mathrm{sm}_{2}$ with vascular infiltration was reported by Shimoda et al. (1989).

According to a nationwide questionnaire about colorectal submucosal cancer, 857 cases were reported by Muto et al. (1991). $12 \%$ of these had lymph node metastases. Radical surgery involving additional bowel resection, following endoscopic or local resection, is selected in most cases in Japan: when any one of the following histopathological findings for the excised tumor is positive: (1) massive invasion remains in or near the stump, (2) vascular infiltration is positive, and the lesion is a (3) moderately or poorly differentiated adenocarcinoma.

The morphological characteristics of colorectal submucosal cancer with lymph node metastasis have not yet been determined. We have reported there was a significant correlation between positive lymph node metastasis and positive budding in advanced colorectal cancer (Araki et al. 1991; Fujiyoshi et al. 1991). In the present study of colorectal submucosal 
cancer, lymph node metastasis was found in $41 \%$ of those cases with positive budding, and in $31 \%$ of those cases with a negative adenomatous component, reflecting the efficacy of these two risk factors. Investigating the relationship between the depth of cancer invasion and the lymph node metastasis revealed no risk with positive lymph node metastasis, with no lymphatic permeation, no budding and not being a moderately or poorly differentiated cancer when invasion was $\mathrm{sm}_{1}$ with only slight infiltration to the lamina muscularis mucosa. This $\mathrm{sm}_{1}$ type of cancer can be treated by local resection, as with mucosal carcinoma. The risk factors such as a moderately differentiated adenocarcinoma with lymphatic permeation, with positive budding and without any adenomatous component are found only in submucosal cancer with invasion of $\mathrm{sm}_{2}$ of deeper, indicating radical surgery with lymphadenectomy is necessary.

In conclusion lymph node metastasis is predicted for colorectal submucosal cancer with a depth of cancer invasion to $\mathrm{sm}_{2}$ or more, or with lymphatic permeation, budding, an adenomatous component, or with a moderately or poorly differentiated adenocarcinoma when additional intestinal resection with lymphadenectomy is indicated.

\section{References}

ArakJ, Y., Isomoto, H., Shirouzu, K., Hayashi, J. and KAKEGAWA, T. (1991). Clinicopathological studies on rectal cancer limited to the muscularis propria. J. Jpn. Soc. Colo-proctol.
44, $105-110$.

Fujiyoshi, M., Isomoto, H., Shirouzu, K., Araki, Y. and Kakegawa, T. (1991). Treatment for early colorectal cancer. J. Jpn. Soc. Colo-proctol. 44, 415-425.

Haggitt, R. C., Glotzbach, R. E. and Soffer, E. E. (1985). Prognostic factors in colorectal carcinomas arising in adenomas: implications for lesions removed by endoscopic polypectomy. Gastroenterology 89, 328-336.

JinNAI, D. (1983). General rules for clinical and pathological studies on cancer of colon, rectum and anus. In Japanese Research Society for Cancer of Colon and Rectum, pp. 7-13. Tokyo: Kanehara Press.

Kudo, S., Soga, J., Y амаmoto, M., Koy ama, S. and Muto, S. (1984). Treatment of colorectal smcarcinomas. I to Cho (Stomach and Intestine) 19, 1349-1356. (in Japanese)

Morodomi, T. (1988). Clinicopathological studies of advanced rectal cancers - prediction the degree of lymph node metastasis from histopathological finding of pre-operative biopsy specimens -. J. Jpn. Surg. Soc. 89, 352-364. (in Japanese)

Morodomi, T., Isomoto, H., Shirouzu, K. and KaKEGAWA, T. (1989). An index for estimating the probability of lymph node metastasis in rectal cancers. Cancer 63, 539-543.

Morson, B. C., Whiteway, J.E. and Jones, E. A. (1984). Histopathology and prognosis of management colorectal polyps treated by endoscopic polypectomy. Gut 25, 437-444.

Muto, T., Nishizawa, M., Kodaira, S., Shimada, T. and TADA, S. (1991). Risk factors of lymph node metastasis of colorectal submucosal carcinoma - A quantitive analysis of 857 cases - I to Cho (Stomach and Intestine) 26, 911-918. (in Japanese).

Shimada, S., Muto, T., Hatakeyama, K., Inoue, Y. and SudA, Y. (1989). Clinicopathological analysis and management of early colorectal cancer with submucosal invasion. Jpn. J. Gastroenterol. Surg. 22, 1108-1115. (in Japanese) 